\title{
A INTERLIGAÇÃO DA PAISAGEM GEOMORFOLÓGICA DA PEDRA FURADA COM A RELAÇÃO HOMEM NATUREZA
}

Nome do Autor (a) Principal

DARLA JULIANA CAVALCANTI MACEDO

Nome (s) do Coautor (a) (s)

JEOVANES LISBOA DA SILVA FILHO

Nome (s) do Orientador (a) (s)

Prof. a Dr. a MARIA BETÂNIA MOREIRA AMADOR

Instituição ou Empresa

UNIVERSIDADE DE PERNAMBUCO - UPE / CAMPUS GARANHUNS-PE

Instituição (s) de Fomento

CNPq - CONSELHO NACIONAL DE DESENVOLVIMENTO CIENTÍFICO E TECNOLÓGICO

E-mail de contato: darlajuliana@hotmail.com

Palavras-chave: Paisagem geomorfológica, relação homem-natureza, sistemismo.

\section{INTRODUÇÃO}

As relações que atualmente desencadeiam as mais variadas questões no âmbito sistêmico geográfico são decorrentes de várias atividades que o homem desenvolve utilizando a natureza, relações essas que são baseadas em um contexto integrante e de muita importância, onde o indivíduo e a sociedade existem de forma interdependente, ou seja, um dependendo do outro. A Geografia estuda essas dependências do homem com a natureza, também de uma forma sistêmica e, para isso faz-se uso dos estudos voltados para o meio ambiente ressaltando-se nesse, as 
relações sistêmicas que se encadeiam uma com a outra, integrando e desenvolvendo uma complexidade que requer formas diferentes de interpretações.

Em relação a essa temática tem-se o intuito de analisar a interligação entre os elementos que compõem a paisagem geomorfológica da Pedra Furada em Venturosa-PE e tem-se como foco de estudos as formas como o homem faz a interação com o meio geoturístico do parque.

Nesse contexto concebe-se a geografia como a ciência que tem como princípios o estudo das partes integradas. Diante disso Mendonça diz que:

A geografia é, sem sombra de dúvida, a única ciência que desde sua formação se propôs ao estudo da relação entre os homens e o meio natural do planeta - o meio ambiente atualmente em voga é propalado na perspectiva que engloba o meio natural e o social (MENDONÇA. 2002, p. 22)

É nesse sentido de integração que rege o meio ambiente e que a geografia se dispõe a analisar que se insere o estudo do Parque Pedra Furada. Toma-se Costa (2000) citado por Amador (2008, p. 81), o qual relata que a estrutura rochosa em questão é caracterizada por "afloramentos rochosos, algumas vezes com aparência de matacões, de origem granítica, os quais aparecem em todas as partes na área, cujo exemplo mais conhecido é o enorme bloco em forma de arco conhecido como Pedra Furada". Isso permite perceber um contexto de complexidade para seu entendimento ao ponto de que para entender essas relações há que se analisarem diferentes fatores bióticos e abióticos que fazem suas relações dinâmicas e sistêmicas.

Quando se fala sobre "homem" pode-se trazer a tona a grande importância que seus sentidos podem lhe proporcionar e, quando a intenção é voltada para a paisagem fica mais evidente que o sentido que mais proeminente é o da visão.

Dos cinco sentidos tradicionais, o homem depende mais conscientemente da visão do que dos demais sentidos para progredir no mundo. Ele é predominantemente um animal visual. Um mundo mais amplo se the abre e muito mais informações, que é espacialmente detalhada e especifica, chega até ele através dos olhos, do que através dos sistemas sensoriais da audição, olfato paladar e tato. A maioria das pessoas, provavelmente considera a visão como sua faculdade mais valiosa e preferia perder uma perna ou tornar-se surda ou muda a sacrificar a visão (TUAN 1980, pag. 7). 
No intuito de trazer essa citação para a área da paisagem turística pode-se afirmar que a visão torna-se o ponto mais importante quando se objetiva fazer uma análise de como o homem vê a Pedra Furada (Figura 1) e a percebe como espaço e lugar.

Figura 1: Vista da Pedra Furada, Venturosa-PE. Foto: Darla Macedo, 2015.

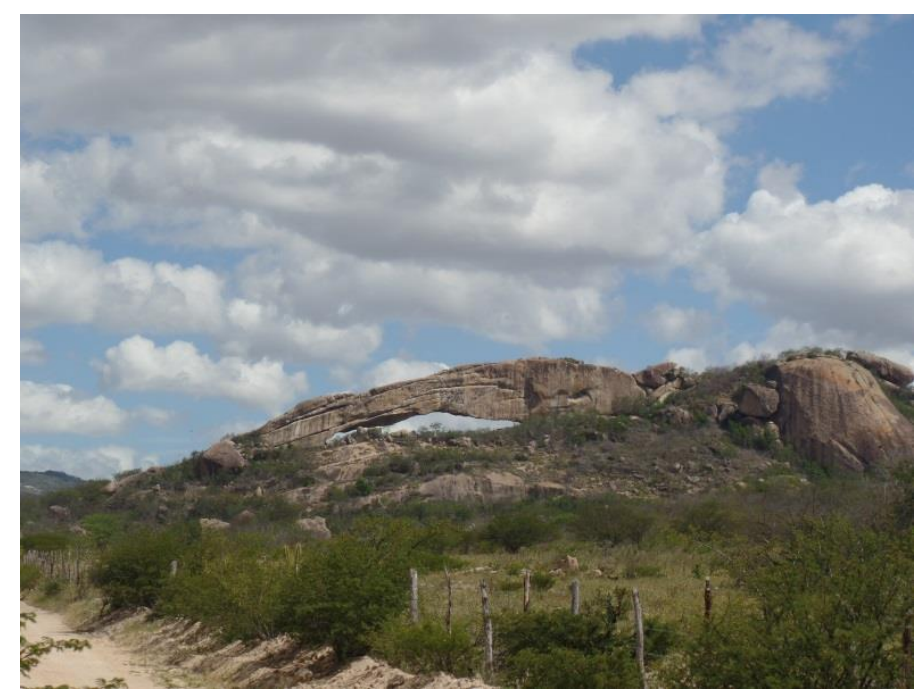

A paisagem da Pedra Furada em sua integração com a vegetação típica da caatinga proporciona uma vista de grande exuberância para a área.

\section{OBJETIVOS}

\section{OBJETIVO GERAL}

Analisar a interligação entre os elementos que compõem a paisagem geomorfológica da Pedra Furada em Venturosa-PE com foco voltado para os estudos das formas como o homem faz a interação com o meio geoturístico do parque.

\section{OBJETIVOS ESPECÍFICOS}


- Analisar a paisagem geomorfológica da Pedra Furada em Venturosa-PE, buscando o entendimento de sua sustentabilidade com baseando-se no embasamento rochoso e sua relação com meio ambiente.

- Caracterizar os aspectos que compõem a vegetação da área em estudo em relação com a fauna e a geomorfologia local.

- Identificar percepções de moradores e do setor público em relação à Pedra Furada.

\section{METODOLOGIA / MÉTODO DE ANÁLISE}

As pesquisas desenvolvidas para o projeto estão baseadas em estudos bibliográficos e, também, de campo, nas quais se tem registrado as informações a respeito do Parque Pedra Furada no município de Venturosa-PE (figura 2). Essas informações estão sendo processadas e gradativamente apresentadas em forma de resumos expandidos com registros fotográficos sobre a área em estudo. A pesquisa ainda está em fase final de desenvolvimento tendo previsão de encerramento para Julho de 2015.

Figura 2: Mapa de localização do município de Venturosa, adaptado por Darla Macedo, 2013.

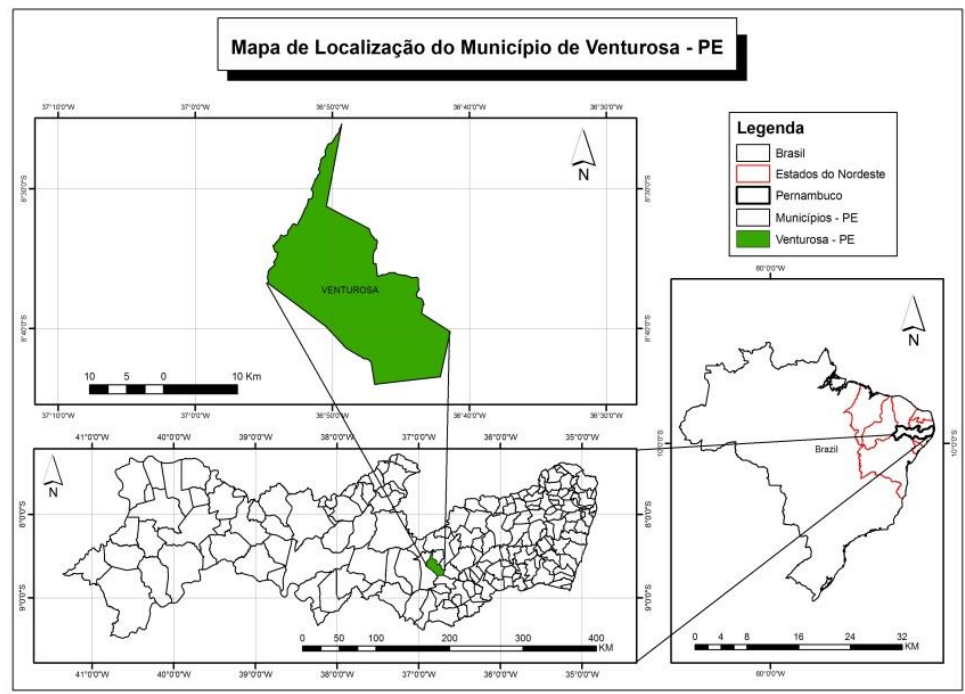

No desenvolvimento do trabalho de campo se justifica a importância de detalhar informações sobre as ocupações existentes no interior e entorno da área 
proposta, como por exemplo, em relação às pessoas que interagem e/ou residem na localidade. Tais informações são consideradas imprescindíveis para 0 aprimoramento da pesquisa como forma de estudar as relações que o homem desenvolve com a natureza seja ela de cunho apreciador ou devastador.

\section{Resultados}

Os resultados obtidos com a pesquisa mescla pontos positivos e negativos no sentido de análise da área. Tem-se na figura 3 a da observação da forma como é tratado o meio ambiente na área com mau descarte dos resíduos sólidos que os turistas deixam na área prejudicando a conservação da mesma, além de falta de consciência dos turistas, também é gritante a falta de interesse das autoridades públicas que não investem no turismo e na conservação ambiental do parque em referencia.

Figura 3 resíduos sólidos descartados em área imprópria foto: Darla Macedo, 2015.

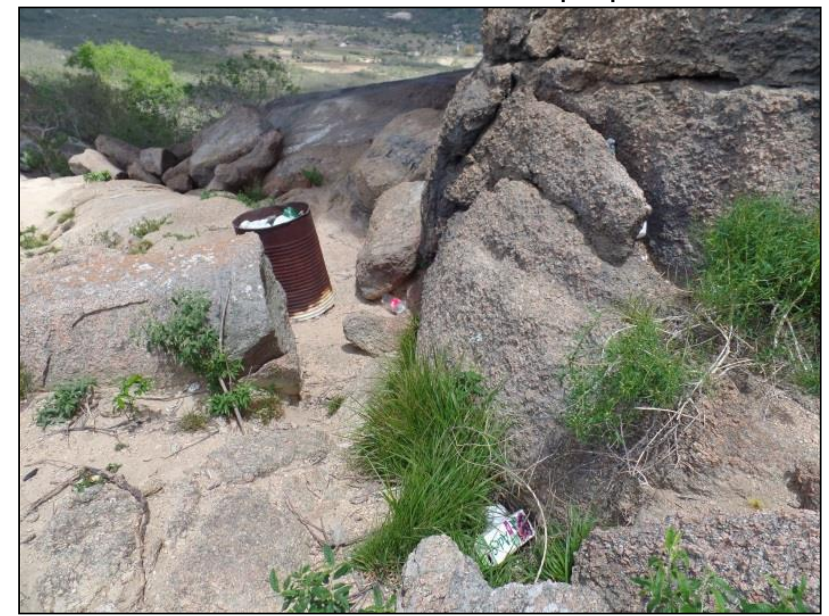

\section{CONCLUSÃO}

A Pedra Furada é um importante ponto turístico não apenas para o município de Venturosa, mais para muitos turistas que fazem do parque um local de visitação para apreciarem a paisagem que a geomorfologia da área apresenta juntamente com vegetação típica de caatinga, as quais estão interligadas de uma forma sistêmica, não havendo assim como separá-las, pois as formas geomorfológicas 
inusitadas da rocha juntamente com a vista que a área propicia dão ao lugar uma paisagem de muita beleza.

Diante disso conclui-se que a área em estudo é de beleza inenarrável mas, por outro lado, faltam políticas públicas que se voltem para a preservação do meio ambiente e, também, por parte dos visitantes da área que ao irem apreciar a beleza da área não a danifiquem deixando lá resíduos sólidos, ou mesmo pichando as rochas. Há que se fazer uso e apreciação das áreas com respeito ao meio ambiente.

\section{REFERÊNCIAS}

AMADOR, Maria Betânia Moreira. Sistemismo e sustentabilidade: questão interdisciplinar. São Paulo: Scortecci, 2011.

A visão Sistêmica e sua contribuição ao estudo do espaço pecuário de Venturosa e Pedra no Agreste de Pernambuco. São Paulo: Blucher Acadêmico, 2008.

ARBEX Júnior, José; BACIC OLIC, Nélson. O Brasil em regiões: Nordeste. São Paulo: Moderna, 1999 (Coleção polêmica).

CASTRO, Cláudio de: JATOBÁ, Lucivânio. Litosfera: minerais, rochas, relevo. 2 ed. Recife: Bagaço, 2006.

MACEDO, D. J. C.; RODRIGUES, R. R. V. ; AMADOR, Maria Betânia Moreira . O JUAZEIRO (Zizyphus joazeiro Mart) NO CONTEXTO RURAL DO MUNICÍPIO DE VENTUROSA-PE. In: IX Fórum Ambiental da Alta Paulista, 2013, Tupã/SP. Periódico Eletrônico Fórum Ambiental da Alta Paulista. Tupã/SP: ANAP, 2013. v. 9. p. 175-180.

MACEDO, D. J. C; RODRIGUES, R. R. V; AMADOR, M. B. M. ESTUDO SOBRE A PEDRA FURADA EM VENTUROSA-PE NUMA PERSPECTIVA SISTÊMICA DA PAISAGEM GEOMORFOLÓGICA Periódico Eletrônico Fórum Ambiental da Alta Paulista-ISSN 1980-0827, Tupã, v. 10, n. 9, p. 9297, 2014. Resumo Expandido apresentado no X Fórum Ambiental da Alta Paulista, Tupã/SP, 2014. Disponível em: <http://www.amigosdanatureza.org.br/publicacoes/index. php/forum_ambiental/article/view/796/820> acesso em 29-04-2015

MENDONÇA, Francisco de Assis. Geografia e meio Ambiente. 6 ed, São Paulo: contexto 2002(Caminhos da Geografia).

MORIN. Edgar. Introdução ao pensamento complexo. Tradução de: Eliane Lisboa. Porto Alegre: Sulina 2005.

TUAN, Yi-Fu. Topofilia. Um estudo da percepção, atitudes e valores do meio ambiente. São Paulo: DIFEL, 1980. Eduel, 2013.

Espaço e lugar: a perspectiva da experiência. Traducao de Livia de Oliveira. Londrina: 